Obituaries / Nachrufe

\title{
Felix Bloch
}

1919-1989

In seinem 70.Lebensjahr ist Felix Bloch, Ehrenmitglied unserer Gesellschaft, am 2. März 1989 gestorben. Einem großen, weit über Europa und Amerika verstreuten Kreis von Interessierten war er sachkundiger und verläßlicher Berater und Lieferant für alte und neue medizinhistorische Bücher und Zeitschriften. Vielen seiner Kunden, darunter auch mir, ist er zum Freund geworden. «Amor librorum nos unit», die hochgreifende Devise der internationalen Antiquariatsbuchhändler, war für ihn eine Wahrheit, in die er auch seine Klienten einbezog.

Felix Bloch ist in einer hochkultivierten Basler Familie jüdischen Ursprungs aufgewachsen. Die Weite des Horizontes, in dem er lebte, mag durch einen Blick auf seine beiden älteren Brüder verdeutlicht werden: der eine, Hubert Bloch, war Forscher auf mikrobiologisch-immunologischem Gebiet; der andere, Alfred Bloch, lehrte Sanskrit und vergleichende Linguistik an der Universität Basel.

Felix Bloch wählte früh seinen eigenen Weg. Nach einem Phil.-I-Studium wurde er Buchhändler und etablierte sich in Lausanne. Die hellere Atmosphäre und die leichtere Lebensart der Romandie sagten ihm besser zu als das traditionsschwere Klima seiner Vaterstadt Basel. Für mich ist er freilich Zeit seines Lebens ein typischer Basler Individualist geblieben, der im besten Baseldytsch seine sarkastisch-witzigen Urteile über die Mitwelt abgab.

In seinem Beruf verband Felix Bloch Natur- und Geisteswissenschaft, indem er ganz besonders die Geschichte der Medizin und der Naturwissenschaften pflegte. Als Buchhändler war er zugleich ein Gelehrter; das zeigten seine Antiquariatskataloge mit ihrer knappen, treffenden Charakterisierung der angebotenen Werke und ihrer Autoren. In Erinnerung bleibt mir auch seine Sprachkultur; die sprachliche Unbeholfenheit gewisser medizinhistorischer Dissertationen erweckte seinen Unwillen. Lange Jahre diente er der SGGMN als Mitglied der Jury für den Sigerist-Preis; hier hat er sich auch 
dafür eingesetzt, daß die Arbeiten junger Westschweizer Autoren gebührend gewürdigt wurden.

Als sich die Zeichen einer chronischen Krankheit einstellten, zog sich Felix Bloch von seiner Stadtbuchhandlung, der Librairie centrale et universitaire in Lausanne, zurück. Unterstützt von seiner Frau, in der letzten Zeit auch von seiner Tochter, konzentrierte er sich in seinem Haus in St-Prex am Lac Léman auf die Pflege und Vermittlung medizinhistorischer Bücher. Den Kennern und Liebhabern alter medizinischer Werke und seinen Freunden stand sein Haus offen, obwohl ihn seine Krankheit quälte und bedrückte.

Felix Bloch hatte den Mut und die Kraft, sein Leben nach seinen eigenen Vorstellungen zu gestalten. Er wird vielen unvergeßlich bleiben.

Huldrych M. Koelbing

NB. Das medizin- und wissenschaftsgeschichtliche Buch-Antiquariat Felix Bloch wird durch seine Tochter weitergeführt:

Mme Françoise Bloch

Route de Rolle 10

CH-1162 St-Prex VD

\section{Hans R.Sauerländer}

1909-1989

Kurze Zeit nach seinem im Familienkreis gefeierten 80. Geburtstag ist in Aarau Herr Hans Remigius Sauerländer gestorben; von der Gründung der Zeitschrift an war er während drei Jahrzehnten unser Verleger.

Das Druck- und Verlagshaus Sauerländer wurde von dem aus Deutschland über Basel zugewanderten Heinrich Remigius Sauerländer-Ryhiner 1807 in Aarau gegründet. Hans R. Sauerländer leitete es zusammen mit seinem Bruder Heinz in fünfter Generation. Er hatte sich auf seinen Beruf gründlich und umfassend vorbereitet. Auf die Maturität an der Kantonsschule Aarau folgte ein Volontariat als Setzer in St. Gallen und anschließend die Ausbildung an der Meisterschule für Deutschlands Buchdrucker in München bis zur Meisterprüfung im Januar 1933. Sprachaufenthalte führ- 
ten Hans R. Sauerländer in die Romandie und nach England; im Stadtverkehr der britischen Metropole bestand der junge Schweizer die Autofahrprüfung. In Volontariaten in Prag und Wien lernte er den Buchhandel, dieses wichtige Zwischenglied zwischen Verleger und Leser, gründlich kennen. Mit 27 Jahren trat er 1936 in den väterlichen Verlag ein. Die Pensionierung (1974) erlaubte Hans R. Sauerländer die Erfüllung eines Wunschtraumes: er siedelte mit seiner Frau in ein Bauernhaus im waadtländischen Villars-sousChampvent über. Die kleine Gemeinde machte sich Sauerländers Vertrautheit mit Geld und Zahlen gleich zunutze und betraute ihn mit der Aufsicht über ihre Finanzen. Familiäre Gründe bewogen ihn jedoch vor einigen Jahren zur Rückkehr nach Aarau.

Ich kam 1970 als Sekretär der SGGMN mit Herrn Hans Sauerländer in Kontakt und hatte in der Folge jedesmal Freude, mit ihm zusammenzukommen und zu verhandeln. Es ging dabei natürlich immer wieder um Termine und vor allem ums Geld. Herr Sauerländer war ein liebenswürdiger, offener Gesprächspartner, der klar und sachlich argumentierte. Trotzdem er sich keineswegs scheute, die harten geschäftlichen Realitäten ins Feld zu führen, die seinen Standpunkt bestimmten, hatte ich stets das Gefühl, der Gesnerus und die monographischen Veröffentlichungen der SGGMN gehörten zu seinen «Lieblingskindern». An den Tagungen unserer Gesellschaft nahm Herr Sauerländer gerne teil, wenn ihn nicht die - aus mir unbekannten Gründen meist gleichzeitig stattfindende - Frankfurter Buchmesse davon abhielt; eine besondere Freude war es mir, ihm 1982 in Basel als Präsident die Ehrenmitgliedschaft der SGGMN zu verleihen. Huldrych M. Koelbing 